\title{
Expression of Concern: A hybrid computational intelligence method for predicting dew point temperature
}

\author{
Mohsen Amirmojahedi ${ }^{1} \cdot$ Kasra Mohammadi ${ }^{2}$ Shahaboddin Shamshirband ${ }^{3} \cdot$ Amir Seyed Danesh $^{4}$. \\ Ali Mostafaeipour ${ }^{5} \cdot$ Amirrudin Kamsin $^{3}$
}

Published online: 12 June 2020

○) Springer-Verlag GmbH Germany, part of Springer Nature 2020

\section{Expression of Concern: Environ Earth Sci (2016) 75:415 \\ https://doi.org/10.1007/s12665-015-5135-7}

The Editors-in-Chief of Environmental Earth Sciences are issuing an editorial expression of concern to alert readers that this article (Amirmojahedi et al. 2016) shows evidence of substantial text overlap [most notably with the articles cited (Mohammadi et al. 2015, 2016; Gocić et al. 2015)] and authorship manipulation. None of the authors responded to correspondence about this editorial expression of concern.

\section{References}

Amirmojahedi M, Mohammadi K, Shamshirband S et al (2016) Environ Earth Sci 75:415. https://doi.org/10.1007/s12665-015-5135-7

The original article can be found online at https://doi.org/10.1007/ s12665-015-5135-7.

Kasra Mohammadi

kmohammadi@umass.edu

$\triangle$ Shahaboddin Shamshirband shamshirband@um.edu.my

Amir Seyed Danesh a.seyeddanesh@gmail.com

1 Department of Civil Engineering, Faculty of Engineering, University of Malaya, 50603 Kuala Lumpur, Malaysia

2 Department of Mechanical and Industrial Engineering, University of Massachusetts, Amherst, MA 01003, USA

3 Department of Computer System and Technology, Faculty of Computer Science and Information Technology, University of Malaya, 50603 Kuala Lumpur, Malaysia

4 Payame Noor University, Rasht branch, Iran

5 Industrial Engineering Department, Yazd University, Yazd, Iran
Mohammadi K, Shamshirband S, Motamedi S et al (2015) Comput Electron Agric 117:214-225. https://doi.org/10.1016/j.compa g.2015.08.008

Mohammadi K, Shamshirband S, Petković D et al (2016) Appl Therm Eng 96:311-319. https://doi.org/10.1016/j.appltherma leng.2015.11.081

Gocić M, Motamedi S, Shamshirband S et al (2015) Comput Electron Agric 113:164-173. https://doi.org/10.1016/j.compa g.2015.02.010

Publisher's Note Springer Nature remains neutral with regard to jurisdictional claims in published maps and institutional affiliations. 